\title{
Colonization of Vitis spp. Wood by sGFP-Transformed Phaeomoniella chlamydospora, a Tracheomycotic Fungus Involved in Esca Disease
}

\author{
Lucia Landi, Sergio Murolo, and Gianfranco Romanazzi
}

Department of Agricultural, Food and Environmental Sciences, Marche Polytechnic University, via Brecce Bianche, 60131 Ancona, Italy. Accepted for publication 10 November 2011.

\begin{abstract}
Landi, L., Murolo, S., and Romanazzi, G. 2012. Colonization of Vitis spp. wood by sGFP-transformed Phaeomoniella chlamydospora, a tracheomycotic fungus involved in Esca disease. Phytopathology 102:290-297.

To evaluate wood colonization and interactions with Vitis spp. of Phaeomoniella chlamydospora, a fungal agent involved in Esca disease, isolate CBS 229.95 was transformed using a pCT74 construct which contained the genetic markers for synthetic green fluorescent protein (sGFP) and hygromycin B phosphotransferase. Nine stable P. chlamydospora fungal transformants ( $P$ ch-sGFP lines) were obtained using polyethyleneglycol-mediated transformation of protoplasts. These were characterized for $s g f p$ and hygromycin B phosphotransferase (hph) genome insertions and for sGFP fluorescence emission, using quantitative polymerase chain

'Sangiovese', 'Biancame', and 'Cabernet Sauvignon'; and the grapevine rootstocks 'Kober 5BB', 'SO4', '420A', '1103P', and V. rupestris were inoculated by immersion in a conidial suspension of the selected fungal $P c h$-sGFP71 line and incubated at $4 \pm 1$ and $25 \pm 1{ }^{\circ} \mathrm{C}$. Wood colonization was estimated through epifluorescence microscopy and was affected by incubation temperature. After 6 months at $4 \pm 1{ }^{\circ} \mathrm{C}$, the fungal growth was completely inhibited. At $25 \pm 1{ }^{\circ} \mathrm{C}$, the highest extent of wood colonization was recorded in Montepulciano and Verdicchio, with the lowest in the rootstocks SO4 and V. rupestris. The expression of the Pch-sGFP71 transformed line was localized in the xylem area, primarily around the vessels. The use of sGFP-transformed $P$. chlamydospora helped to clarify different aspects associated with the location of this pathogen in grapevine tissue, before disease symptom expression.
\end{abstract} reaction and fluorimetric systems, respectively. No correlation was observed between $s g f p$ copy number genome insertion and sGFP fluorescence expression. Cuttings of Vitis vinifera 'Montepulciano', 'Verdicchio',
Additional keywords: quantitative real-time polymerase chain reaction.
Esca is one of the most destructive grapevine trunk diseases (9). The complexity of Esca disease is due to its etiology. Fungi associated with Esca symptoms include the hyphomycetes Phaeomoniella chlamydospora and Phaeoacremonium spp., which are associated with black streaking and brown-red wood $(12,19)$. It is the combination of these fungi with the wood-rotting basidiomycete Fomitiporia mediterranea that causes "Esca proper", affecting mostly older vines (40), whereas young vines showing Esca foliar symptoms, wood black streaking, and necrosis are mainly infected by $P$. chlamydospora or Phaeoacremonium spp. Recently, symptomatic vines have been frequently recorded in 2- to 3-year-old vineyards and, from such plants, P. chlamydospora and $P$. aleophilum are consistently isolated (30,35). A histochemical study of necrotic wood tissue of vines infected with $P$. chlamydospora revealed that the fungus was spread through the xylematic area $(43,44)$. On the other hand, P. chlamydospora, when artificially inoculated, did not completely succeeded in reproducing the syndrome of young Esca (40). P. chlamydospora may even be isolated from apparently healthy rootstock mother plants $(15,35,46)$ and from cuttings $(5,17)$. This, indeed, raises questions about the possible role of nurseries in propagating pathogens associated with Esca in the field.

Studies of fungal colonization in plants using fungal transformation with a vital marker can allow the fungal structures to be

Corresponding author: G. Romanazzi; E-mail address: g.romanazzi@univpm.it

* The $e$-Xtra logo stands for "electronic extra" and indicates that the online version contains one supplemental figure.

http://dx.doi.org/10.1094/PHYTO-06-11-0165

(C) 2012 The American Phytopathological Society traced in the plant host, independent of the expression of disease symptoms. Monitoring fungal colonization - in particular, $P$. chlamydospora - in grapevine cuttings can provide information to better understand disease epidemiology. The synthetic green fluorescent protein ( $s g f p$ ) gene from the jellyfish Aequorea victoria, which encodes GFP, has been widely used as a reporter gene in a large number of organisms. Such fluorescent genes are useful for tracking proteins in living cells; as reporters of promoter activity; as labels to visualize specific tissues, whole cells, or subcellular organelles; and for monitoring of gene expression and protein localization. This protein is a successful reporter because only UV or blue light and oxygen are needed for its visualization, and not cofactors or substrates, as is often the case for other reporters. Indeed, this gene and its variants are the most widely used reporters in biological research (22). Expression of GFP has been described in many different filamentous fungal genera, including Fusarium, Botrytis, Pyrenophora, Alternaria, Cochliobolus, Sclerotinia, Colletotrichum, and Verticillium (24). $P$. chlamydospora has been transformed with GFP previously and characterized according to its morphological and pathogenetic features $(7,28)$. However, host colonization of $P$. chlamydospora (Pch)-sGFP on grapevine cuttings has not yet been investigated.

The aim of this study was to develop a procedure for in situ analysis of the spread of $P$. chlamydospora in grapevine and rootstock cuttings before the disease symptoms become apparent, using this sGFP reporter. To reach this main objective, we developed a fungal transformation procedure and a protocol to characterize the fungal sGFP transformants, both by a molecular method (quantitative real-time polymerase chain reaction [PCR]), and in vivo by a fluorimetric method (fluorescence emission). 


\section{MATERIALS AND METHODS}

Preparation of protoplasts, transformation, and selection of $P$. chlamydospora transformants. Transformation was performed on P. chlamydospora CBS 229.95 type strain. To obtain protoplasts, $P$. chlamydospora was grown on potato dextrose agar (PDA) (Micropoli, Legnano, Milan, Italy) at $23 \pm 1^{\circ} \mathrm{C}$ for 20 days; then, $300 \mathrm{mg}$ of fungal mycelium was scraped from the plates and inoculated into $250-\mathrm{ml}$ flasks containing $100 \mathrm{ml}$ of potato dextrose broth. These were incubated for 7 days in the dark at $25 \pm$ $1{ }^{\circ} \mathrm{C}$ in an orbital shaker at $150 \mathrm{rpm}$. The mycelia were pelleted by centrifugation at $2,500 \times g$ for $10 \mathrm{~min}$, rinsed with sterile distilled water, resuspended in a petri dish with lysis buffer $(15 \mathrm{ml}$ of $1.4 \mathrm{M} \mathrm{MgSO}_{4}$ and $10 \mathrm{mM} \mathrm{Na}_{2} \mathrm{HPO}_{4}, \mathrm{pH}$ 5.8) containing lysozyme (L7651; Lysozyme from chicken egg white) (SigmaAldrich, St. Louis) at $10 \mathrm{mg} / \mathrm{ml}$, and incubated at $30 \pm 0.5^{\circ} \mathrm{C}$ for $4 \mathrm{~h}$. The enzyme-protoplast solution was then filtered through a nylon membrane $(50 \mu \mathrm{m})$. Aliquots of $5 \mathrm{ml}$ were placed in centrifuge tubes and overlaid with $2 \mathrm{ml}$ of $1 \mathrm{M}$ sorbitol and $50 \mathrm{mM}$ Tris- $\mathrm{HCl}, \mathrm{pH}$ 8.0. After centrifugation at $800 \times g$ for $5 \mathrm{~min}$, the protoplasts were collected from the interface and resuspended in $1.2 \mathrm{M}$ sorbitol, $50 \mathrm{mM} \mathrm{CaCl}_{2}$, and $50 \mathrm{mM}$ Tris- $\mathrm{HCl}$, $\mathrm{pH}$ 8.0. The viability and quantity of the protoplasts were assessed using the fluorescein diacetate staining method (47) and observed in a hemocytometer chamber using epifluorescent Nikon Diaphot TMD inverted microscope (Nikon, Tokyo), equipped with a blue filter block B-2A (excitation filter, EX450-490; barrier filter, BA 520) (Nikon).

The pCT74 plasmid vector was kindly provided by Prof. L. Ciuffetti (Oregon State University) and contained the $s g f p$ driven by the ToxA gene promoter of Pyrenophora tritici-repentis and the hygromycin B phosphotransferase $(h p h)$ gene, which can induce hygromycin B resistance (24). This vector was used to transform the fungus using a polyethylene glycol (PEG)-mediated system.

In all, $\approx 10 \mu \mathrm{g}(1 \mu \mathrm{g} / \mu \mathrm{l})$ of plasmid DNA was added to $200 \mu \mathrm{l}$ of

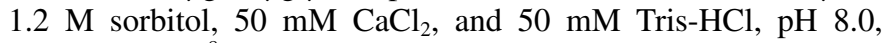
containing $\approx 10^{8}$ protoplasts that showed 80 to $90 \%$ viability, with $10 \mu \mathrm{l}$ of $20 \mathrm{mM}$ aurintricarboxylic acid (Sigma-Aldrich), $5 \mu \mathrm{l}$ of $50 \mathrm{mM}$ spermidine (Sigma-Aldrich), and $100 \mu \mathrm{g}$ of heparin (Sigma-Aldrich) added to improve the PEG-mediated transformation (16). After an incubation of $30 \mathrm{~min}$ on ice and the addition of $60 \%$ PEG 6000 in $1.2 \mathrm{M}$ sorbitol, $50 \mathrm{mM} \mathrm{CaCl}_{2}$, and $50 \mathrm{mM}$ Tris$\mathrm{HCl}, \mathrm{pH} 8.0$, in three successive steps of 250,250 , and $850 \mu \mathrm{l}$, the mixture was kept for $30 \mathrm{~min}$ at $25 \pm 1{ }^{\circ} \mathrm{C}$ and plated on PDA supplemented with $0.8 \mathrm{M}$ sucrose. The cultures were incubated for 7 days at $28^{\circ} \mathrm{C}$. Experiments were repeated three times.

Fungal tip colonies grown on PDA supplemented with $0.8 \mathrm{M}$ sucrose were transferred onto PDA amended with hygromycin B at $100 \mathrm{mg} / \mathrm{liter}$ (PDAhyg) for 20 days. The stability of the transformants was tested by subculturing three times on a nonselective medium (PDA without the antibiotic) and then checking again for their ability to grow on PDAhyg. To evaluate the stability of the sgfp gene insertion into the fungal genome, preliminary analyses were performed for the emission of fluorescence from mycelium of sGFP-transformed colonies, using an epifluorescent Nikon Diaphot TMD inverted microscope (Nikon) equipped with a blue filter block B-2A (Nikon). To confirm the presence of both the $s g f p$ and $h p h$ genes, PCR was performed on DNA from putative transformants and the CBS 229.95 wild-type strain using genespecific primers (Table 1). Genomic DNA was isolated from the mycelia of the $P$ ch-sGFP lines using a previously published cetyltrimethylammonium-bromide (CTAB)-based DNA extraction procedure (31), with minor modifications. Briefly, $100 \mathrm{mg}$ of mycelium, ground in liquid nitrogen, was suspended in $1 \mathrm{ml}$ of extraction buffer (100 mM Tris- $\mathrm{HCl}[\mathrm{pH} 8.0], 1.4 \mathrm{M} \mathrm{NaCl}$, $20 \mathrm{mM}$ EDTA, 2\% CTAB, and $0.4 \% \beta$-mercaptoethanol) and incubated at $65^{\circ} \mathrm{C}$ for $20 \mathrm{~min}$. The samples were extracted with an equal volume of chloroform/octanol (24:1) and centrifuged at $7,500 \times g$ for $10 \mathrm{~min}$. The supernatants were transferred to fresh tubes and nucleic acids were precipitated by adding 0.6 volume of isopropanol. After centrifugation $(13,000 \times g$ for $15 \mathrm{~min})$, the supernatants were discarded and the DNA pellets were rinsed with $70 \%$ ethanol, and resuspended in Tris-EDTA buffer $(10 \mathrm{mM}$ Tris- $\mathrm{Cl}$ and $1 \mathrm{mM}$ EDTA, $\mathrm{pH}$ 8.0). PCR conditions for detection of $s g f p$ and $h p h$ comprised one cycle at $95^{\circ} \mathrm{C}$ for $8 \mathrm{~min}$; followed by 35 cycles at $95^{\circ} \mathrm{C}$ for $50 \mathrm{~s}, 55^{\circ} \mathrm{C}$ for $30 \mathrm{~s}$, and $72^{\circ} \mathrm{C}$ for $50 \mathrm{~s}$; and a supplementary extension of $5 \mathrm{~min}$ at $72^{\circ} \mathrm{C}$. The $P$. chlamydospora species-specific primer $\mathrm{OPA} 13_{844}(1,35)$ was used to confirm the identity of the transformants. All the PCR reactions contained $10 \mu \mathrm{l}$ of $2 \times$ Taq PCR Master Mix kit (Qiagen, Hilden, Germany), $1 \mu \mathrm{M}$ each primer, and $50 \mathrm{ng}$ of total DNA. The transformants were subcultured five more times on PDAhyg. After this selection step, nine transformant colonies that showed similar morphological growth and features compared with wildtype $P$. chlamydospora were selected and characterized by quantitative (q)PCR and for sGFP expression using a Nikon P101 microscopy photometer (Nikon).

$\boldsymbol{P c h}$-sGFP lines characterized by qPCR molecular analysis of gene integration. Insertion of the $s g f p$ and $h p h$ genes into the fungal genome was checked by qPCR using SYBR Green technology. The relative copy numbers of the $s g f p$ and $h p h$ target genes were calculated using the comparative quantification $\Delta \mathrm{Cq}$ method (23). As a reference, the $\beta$-tubulin and elongation factor$1 \alpha(E F 1-\alpha)$ genes were used (Table 1), because they have been previously described in other filamentous fungi as single-copy regions within the genome $(25,33,38)$. All of the primers were selected using the Primer3 software (36).

The $s g f p$ and $h p h$ gene copy numbers were determined accord-

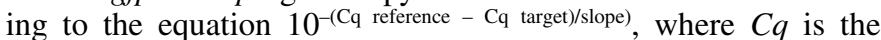
quantification cycle and reflects the cycle number at which the fluorescence generated within the reaction of each sample crosses the threshold. The transgene targets were the $s g f p$ and $h p h$ genes, the references were the $\beta$-tubulin and EFl- $\alpha$ genes, and the slope was calculated according to the standard curves, which were

TABLE 1. Primer sequences, reference accession numbers (National Center for Biotechnology Information [NCBI]), and polymerase chain reaction product sizes for confirming the presence and copy number of each gene in Phaeomoniella chlamydospora

\begin{tabular}{|c|c|c|c|c|}
\hline Gene & NCBI accession number & Primer sequence $\left(5^{\prime} \rightarrow 3^{\prime}\right)$ & $\mathrm{TM}\left({ }^{\circ} \mathrm{C}\right)^{\mathrm{w}}$ & Amplicon (bp) \\
\hline \multirow[t]{2}{*}{$s g f p^{\mathrm{x}}$} & GU045599.1 & TATATCATGGCCGACAAGCA & 60.5 & 219 \\
\hline & & GAACTCCAGCAGGACCATGT & 60.0 & $\cdots$ \\
\hline$h p h^{\mathrm{y}}$ & AY142483.1 & ATCTTAGCCAGACGAGCG & 59.0 & 360 \\
\hline$\beta$-tubulin & & TGAGCATCGTTCTTGTCTGG & 59.8 & 100 \\
\hline \multirow[t]{2}{*}{$E F 1-\alpha^{\mathrm{z}}$} & EU158825.1 & CTCAAAACGACCCTTGCTTC & 60.5 & 165 \\
\hline & $\ldots$ & GCCTTGAGCTTGTCCAAAAC & 59.4 & $\cdots$ \\
\hline
\end{tabular}

\footnotetext{
${ }^{\text {w }}$ Predicted melting temperature.

${ }^{x}$ Synthetic green fluorescent protein

${ }^{y}$ Hygromycin B phosphotransferase.

${ }^{\mathrm{z}}$ Elongation factor- $1 \alpha$.
} 
specific for each gene (Supplementary Figure S1). Standard curves for the target and reference genes were obtained from the $P c h$-sGFP51 transformant, because this transformant showed the highest $C q$ value according to our preliminary $\mathrm{qPCR}$ analysis, using 10-fold serial dilutions of 10 to $10^{-2} \mathrm{ng}$. The standard curve efficiencies were $100.2,101.5,99.3$, and $101.7 \%$ for the $s g f p$, hph, $\beta$-tubulin, and EFl- $\alpha$ genes, respectively, with slopes of $-3.318,-3.286,-3.340$, and -3.283 , respectively. The high efficiency for each gene allowed the assumption that the genes are amplified with the same efficiency, and an average slope of -3.306 was used in the equation. DNA from the $P c h$-sGFP lines and from $P$. chlamydospora wild-type (negative control) was quantified with the VersaFluor Fluorometer system (Bio-Rad, Hercules, CA). The study was carried out in an iCycler iQ Multicolor RealTime PCR Detection system (Bio-Rad). The reaction mixture was prepared in a final volume of $22 \mu$, including $11 \mu \mathrm{l}$ of $2 \times$ SYBR Green I (Bio-Rad), $1 \mu \mathrm{l}$ of forward and reverse primers $(0.1 \mu \mathrm{M}$ each), and $9 \mu \mathrm{l}$ of diluted DNA (1.8 ng for each sample). The following thermal cycling conditions were used: one cycle at $95^{\circ} \mathrm{C}$ for $8 \mathrm{~min}$ followed by 40 cycles at $95^{\circ} \mathrm{C}$ for $40 \mathrm{~s}, 55^{\circ} \mathrm{C} 30 \mathrm{~s}$, and $72^{\circ} \mathrm{C}$ for $40 \mathrm{~s}$. Fluorescence was read during the annealing step or during the extension at $72^{\circ} \mathrm{C}$. The specificity of the amplicons for all of the PCR reactions was verified by melting curves. These cycles were performed at temperature increases of $0.05^{\circ} \mathrm{C} / \mathrm{s}$, from 55 to $95^{\circ} \mathrm{C}$. All of the genes were assayed in the same plate, with each in duplicate, and the experiments were repeated three times.

In vivo fluorescence emission of the $P$ ch-sGFP lines. The fluorescence intensity of the $P c h$-sGFP mycelia was measured. Three replicates of selected $P c h$-sGFP lines were cultured for 10 days in PDAhyg media. The $P$. chlamydospora strain CBS 229.95 was included as a control. Mycelia (200 mg) was collected and resuspended in $1.0 \mathrm{ml}$ of sterile distilled water. The suspensions obtained (three from each $P$ ch-sGFP line) were placed in 30-mm-diameter petri dishes and their fluorescence emission was examined using a Nikon System P101S photometer linked to an epifluorescent Nikon Diaphot TMD inverted microscope (Nikon), equipped with a blue filter block B-2A (Nikon) and a Nikon $\times 20 / 5.0$ NA (objective magnification/numerical aperture field diaphragm). Thirty single measurements were taken for each subculture replication. The exposure time for each measurement was $<2$ s. The fluorescence background was calculated according to the $P$. chlamydospora CBS 229.95 wild-type used as the control. Experiments were repeated twice.

Colonization of Pch-sGFP71 in Vitis spp. In winter 2007, cuttings from Vitis vinifera ('Montepulciano', 'Verdicchio', 'Sangiovese', 'Biancame', and 'Cabernet Sauvignon') and the rootstocks 'Kober 5BB' $(V$. berlandieri $\times$ V. riparia $)$, 'SO4' $(V$. berlandieri $\times$ V. riparia), '420A' $(V$. berlandieri $\times V$. riparia $)$, ' $1103 \mathrm{P}$ ' ( $V$. berlandieri $\times V$. rupestris), and $V$. rupestris were collected from a mother plant vineyard located in Ascoli Piceno, in the Marche region (central-eastern Italy). The sanitary status of mother plants was monitored by visual inspections twice in the year and assessed by immuno-enzymatic and molecular tools for the detection of the main grapevine viruses and fungi involved in Esca complex, respectively.

The Pch-sGFP71 line was grown on PDAhyg dishes for 2 weeks. Conidia and mycelia were collected by rinsing each petri dish and gently scraping the colony surface with a glass rod in the presence of $10 \mathrm{ml}$ of $0.1 \%$ Triton X-100. The suspensions were filtered through sterile double-layer cheesecloth. The concentrations of the suspension were adjusted to $1 \times 10^{7} \mathrm{CFU} / \mathrm{ml}$ using a spectrophotometer reading at a $425-\mathrm{nm}$ wavelength $(=1=1 \times$ $10^{8} \mathrm{CFU} / \mathrm{ml}$ ) adapted from Romanazzi et al. (34). With the aim to reproduce nursery storage conditions of the cuttings, two different incubation temperatures at $4 \pm 1$ and $25 \pm 1{ }^{\circ} \mathrm{C}$ were tested for both inoculated cultivars and rootstocks. For each incubation temperature, four groups of 1070 -cm-long cuttings were prepared, and their bottom ends were aligned. Three of these groups were inoculated with the Pch-sGFP71 conidial suspension and one group with water (control) for $12 \mathrm{~h}(\leq 5 \mathrm{~cm}$ from the bottom of the cuttings). After inoculation, the bottom section of each cutting was covered with cotton soaked in water, enclosed in plastic bags, and stored for 6 months.

After incubation for 6 months at 4 and $25 \pm 1{ }^{\circ} \mathrm{C}, 2030-\mu \mathrm{m}-$ thick transverse sections were cut from each sample, using a cryomicrotome (HM505E microtome; Microm Laborgeräte, Walldorf, Germany). These were selected from along the stem (two sections for each $5 \mathrm{~cm}$ ) and analyzed using an epifluorescent Diaphot TMD inverted microscope, with a blue filter block B-2A (Nikon). Thirty cuttings were analyzed per group, and the colonization levels were expressed as centimeters from the bottom of each cutting, according to the stem fragments that showed green fluorescence. In order to correlate the presence of the PchsGFP71 with the epifluorescence signal, $P$. chlamydospora and s $g f p$ molecular detection was carried out by PCR, using specific primer pairs as previously described, on 30 randomly selected sections, 20 from portions of inoculated cuttings showing brilliant green fluorescence and 10 from portions of inoculated cuttings showing orange-yellow fluorescence, the typical color observed on control cutting tissue by an epifluorescent microscope. Moreover, to confirm the stability of $P$ ch-sGFP71 line, the fungus was reisolated on PDA from 30 inoculated cutting sections showing green fluorescence by incubation in a humid chamber at $25 \pm 1^{\circ} \mathrm{C}$ for $48 \mathrm{~h}$, and observed under epifluorescent microscopy (Nikon).

Statistical analysis. Data collected from molecular analysis of sgfp and hph P. chlamydospora gene integration, in vivo fluorescence of the Pch-sGFP lines, and extent of colonization of PchsGFP71 in Vitis spp. were statistically evaluated for means comparison, and significant differences were separated using Duncan's multiple range tests $(P \leq 0.05)$ after analysis of variance. sGFP expression and the $s g f p$ DNA copy numbers, which were calculated in $P c h$-sGFP lines as previously described, were correlated using Pearson linear correlation $(P \leq 0.05)$. Pearson correlation coefficients $(r)$ and probabilities $(P)$ of the significance test for correlation were calculated for the $\beta$-tubulin and EF1- $\alpha$ references genes.

\section{RESULTS}

Protoplast isolation and transformation efficiency. The $P$. chlamydospora isolate CBS 229.95 generated a high protoplast yield and was efficiently transformed using this PEG-mediated method and the pCT74 plasmid containing both the sgfp and hph genes. A mean of 6 to $8 \times 10^{6}$ protoplasts $/ \mathrm{ml}$ was generated from $300 \mathrm{mg}$ of mycelium. Based on vital staining with fluorescein diacetate, the viability of the $P$. chlamydospora protoplasts was 85 to $95 \%$. The transformation experiments yielded $\approx 60$ individual hygromycin-resistant transformants after the first subculture in PDAhyg. After three successive subcultures on PDA and one on PDAhyg, there were 24 (40\%) stably transformed fungal colonies. The stability of these transformants was evaluated after five subsequent subcultures on PDAhyg. All of the Pch-sGFP transformants continued to express sGFP after 12 months of consecutive subculturing on PDA. From this group, nine $P c h$-sGFP lines were selected and characterized.

Molecular characterization of Pch-sGFP lines. PCR analysis confirmed the presence of both the $s g f p$ and $h p h$ genes in all of the 24 transformants. No $s g f p$ - and $h p h$-specific amplicons were obtained in the wild-type P. chlamydospora used as the control. PCR with species-specific $P$. chlamydospora primers confirmed the species identity (data not shown).

The qPCR analysis was performed to determine the $s g f p$ and $h p h$ copy numbers in each of the nine selected $P$. chlamydospora transformants and showed the same results using $\beta$-tubulin or $E F 1-\alpha$ as the reference normalizing genes (Table 2). Although 
equal amounts of genomic DNA were analyzed, different $s g f p$ and $h p h$ relative copy numbers were observed across these different $P$. chlamydospora lines, which indicates that the integration of the construct occurred at multiple sites. The multiple-copy integration seen for $s g f p$ and $h p h$ was from twofold to sixfold the reference genes. By comparing the results for each line, seven of nine PchsGFP lines showed the same number of integrated copies of $s g f p$ and $h p h$, while differences were seen for the Pch-sGFP62 line (six copies of $s g f p$ and four copies of $h p h$, compared with the reference genes) and for the $P c h$-sGFP11 line (four copies of $s g f p$ and three copies of $h p h$, compared with the reference genes).

$\boldsymbol{P c h}$-sGFP line fluorescence intensities. Epifluorescence microscopy analysis of all of the selected Pch-sGFP expressing lines showed uniform bright green fluorescence in the growing hyphal tips. Fluorescence measurements of mycelial plugs of selected $P c h$-sGFP lines showed higher fluorescence values with respect to the fluorescence background detected with $P$. chlamydospora wild-type $(P \leq 0.05)$, which ranged from 23.5 -fold ( $P$ ch-sGFP32) to 49.6-fold ( $P$ ch-sGFP71). However, significant differences in the fluorescence intensities were observed across the $P c h$-sGFP lines. The lowest sGFP fluorescence intensity values were recorded for $P$ ch-sGFP81, Pch-sGFP82, and Pch-sGFP32 (<200), while the highest value was seen for Pch-sGFP71 (>350) (Fig. 1). Moreover, $P c h$-sGFP71 showed the same copy numbers of $s g f p$ and $h p h$ genes (Table 2).

A low relationship between sGFP fluorescence expression and $s g f p$ gene copy was observed in the $P c h$-sGFP lines analyzed (Fig. 2). The Pearson's correlation coefficients were $r=0.41, P=$ 0.27 using the $\beta$-tubulin reference gene and $r=0.45, P=0.22$ based on the $E F 1-\alpha$ gene $(P \leq 0.05)$.

Colonization of $\boldsymbol{P}$ ch-sGFP71 in Vitis spp. The $P$ ch-sGFP71 line, showing both the highest sGFP fluorescence emission and the same copy number of sgfp and $h p h$ genes, was selected in our study on Vitis spp. colonization. Cultivars and rootstocks inoculated with $P$ ch-sGFP71 showed wide black discoloration along the bases of the cuttings. However, the wood disease symptoms were not indicative of $P$. chlamydospora colonization, because sGFP-specific green fluorescence was observed in symptomless wood sections from inoculated cuttings of the cultivars and rootstocks. These symptomless sections from inoculated cuttings that showed green fluorescence were analyzed using the P. chlamydospora and $s g f p$-specific primers, and Pch-sGFP71 was detected by PCR (data not shown).

Direct epifluorescence microscopy analysis of sections obtained from inoculated cuttings showed different extents of $P$. chlamydospora colonization and it was affected by incubation temperature. A higher extent of growth was observed in cultivar and rootstock cuttings incubated at $25 \pm 1{ }^{\circ} \mathrm{C}$ after 6 months of incubation, compared with the cuttings incubated at $4 \pm 1^{\circ} \mathrm{C}$ for the same period. Montepulciano and Verdicchio showed the highest fungal colonization at 31.8 and $30.2 \mathrm{~cm}$ from the bottom of the cuttings, respectively. The lowest levels of colonization were in Cabernet Sauvignon $(12.0 \mathrm{~cm})$ and the V. rupestris $(10.4$ $\mathrm{cm})$ and SO4 $(8.0 \mathrm{~cm})$ rootstocks. The other cultivars (Sangiovese and Biancame) and rootstocks (Kober 5BB, 420A, and 1103P) analyzed showed intermediate $P$ ch-sGFP colonization (Fig. 3). On the other hand, at $4 \pm 1{ }^{\circ} \mathrm{C}$, all of the analyzed cultivars and rootstocks showed reduced $P c h$-sGFP colonization that was localized only in the basal section (data not shown). However, fungal viability was preserved, as demonstrated by the development of the mycelium on the cutting section from canes stored at $4 \pm 1^{\circ} \mathrm{C}$ for 6 months and then incubated at $25 \pm 1^{\circ} \mathrm{C}$ for 72 and $96 \mathrm{~h}$ (Fig. 4A and B).

After 6 months, in the inoculated cuttings stored at $25 \pm 1{ }^{\circ} \mathrm{C}$, the epifluorescent microscopy revealed brilliant green fluorescence in the xylem tissue (Fig. 4C to F), while a uniform yellowbrown coloration in control samples was observed (Fig. 4G, 4H). Analysis of the transverse sections showed the P. chlamydosporaspecific green fluorescence in the secondary xylem. In particular,

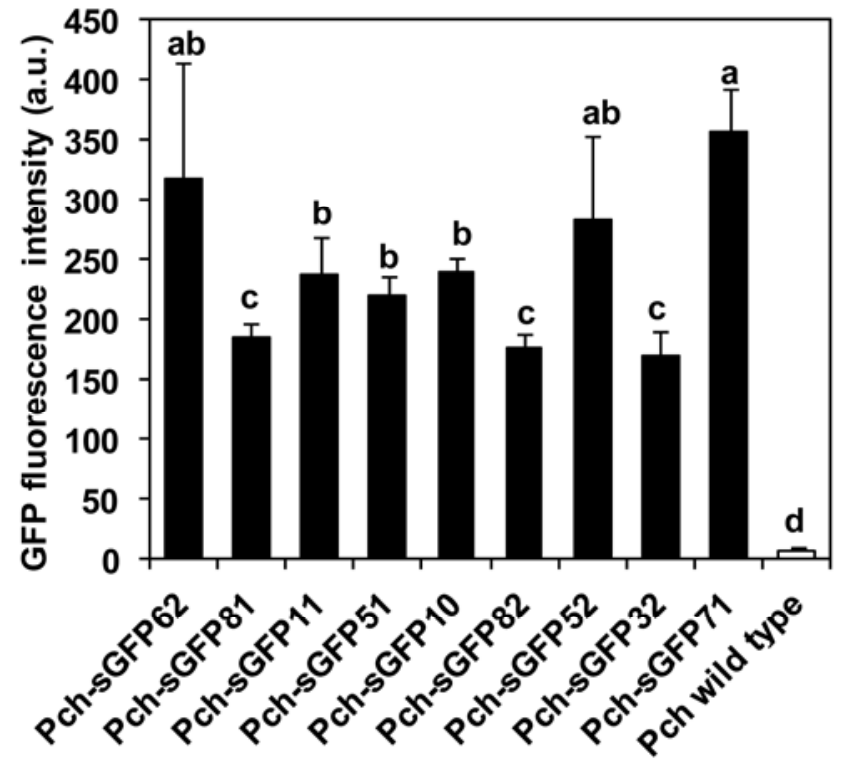

\section{Phaeomoniella chlamydospora isolate}

Fig. 1. Intensity of synthetic green fluorescent protein (sGFP) fluorescence (expressed as arbitrary units [a.u.]) of the mycelia of the nine Phaeomoniella chlamydospora $(P c h)$-sGFP lines and $P$. chlamydospora wild-type (as indicated). Data are means ( \pm standard deviation) of 30 single measurements for each of three subcultured $P$ ch-sGFP lines, with each repeated twice per $P c h$ sGFP line. Columns with different letters are significantly different according to Duncan's multiple range test $(P \leq 0.05)$.

TABLE 2. Average quantification cycles (Cq) and relative copy numbers of synthetic green fluorescent protein (sgfp) and hygromycin B phosphotransferase ( $h p h$ ) genes detected by quantitative polymerase chain reaction analyses and calculated with the $\Delta \mathrm{Cq}$ comparison method ${ }^{\mathrm{X}}$

\begin{tabular}{|c|c|c|c|c|c|c|c|c|}
\hline \multirow[b]{2}{*}{ Isolates } & \multicolumn{4}{|c|}{$C q$ value } & \multicolumn{2}{|c|}{$\beta$-tubulin ${ }^{\mathrm{y}}$} & \multicolumn{2}{|c|}{$E F 1-\alpha^{\mathrm{z}}$} \\
\hline & $\beta$-tubulin & $E F 1-\alpha$ & $s g f p$ & $h p h$ & $s g f p$ & $h p h$ & $s g f p$ & $h p h$ \\
\hline$P c h$-sGFP62 & $18.2 \pm 0.05$ & $18.7 \pm 0.05$ & $15.6 \pm 0.10$ & $16.2 \pm 0.05$ & $5.9 \mathrm{a}$ & $4.0 \mathrm{~b}$ & $5.6 \mathrm{a}$ & $3.8 \mathrm{~b}$ \\
\hline$P c h$-sGFP81 & $16.9 \pm 0.05$ & $16.9 \pm 0.15$ & $14.9 \pm 0.15$ & $15.1 \pm 0.15$ & $4.1 \mathrm{a}$ & $3.9 \mathrm{a}$ & $4.0 \mathrm{a}$ & $3.8 \mathrm{a}$ \\
\hline$P c h$-sGFP51 & $16.4 \pm 0.20$ & $16.4 \pm 0.10$ & $15.3 \pm 0.05$ & $15.4 \pm 0.25$ & $2.2 \mathrm{a}$ & $2.2 \mathrm{a}$ & $2.2 \mathrm{a}$ & $2.1 \mathrm{a}$ \\
\hline Pch-sGFP10 & $17.6 \pm 0.05$ & $17.5 \pm 0.05$ & $15.5 \pm 0.10$ & $15.5 \pm 0.05$ & $4.3 \mathrm{a}$ & $4.1 \mathrm{a}$ & $4.0 \mathrm{a}$ & $3.8 \mathrm{a}$ \\
\hline Pch-sGFP82 & $17.6 \pm 0.20$ & $17.5 \pm 0.10$ & $15.5 \pm 0.15$ & $15.6 \pm 0.05$ & $4.4 \mathrm{a}$ & $4.1 \mathrm{a}$ & $4.2 \mathrm{a}$ & $4.0 \mathrm{a}$ \\
\hline
\end{tabular}

${ }^{\mathrm{x}}$ Data reported relative to $\beta$-tubulin and elongation factor 1- $\alpha(E F 1-\alpha)$ genes were used as references. Means in each column followed by the same letter are not significantly different according to Duncan's multiple range test $(P<0.05)$.

${ }^{y}$ Gene copies with $\beta$-tubulin as calibrator.

${ }^{\text {z }}$ Gene copies with $E F 1-\alpha$ as calibrator. 
Pch-sGFP71 colonized tissues around vessels, including the xylem fibers and the paratracheal parenchyma cells surrounding the vessels. Moreover, it was noted that there were complete or partial occlusions of the vessel lumens by compounds characterized by an orange coloration, which was also observed in the axial parenchyma. In contrast, the vessel lumens of nonfluorescent areas were usually empty (Fig. 4C and D). Analysis of the longitudinal sections confirmed the Pch-sGFP71 colonization (Fig. 4E and F), and the presence of compounds which were responsible for the occlusion of the vessel lumens was detected near the vessel according to the intense green fluorescence (Fig. 4F). No specific green fluorescence was observed into the vessels of the longitudinal sections (Fig. 4F).

The molecular analysis performed on selected sections from inoculated cuttings revealed the presence of the $s g f p$ and $P$. chlamydospora genes in all of the sections showing a brilliant green fluorescence, while none were detected in sections without specific green fluorescence (data not shown).

\section{DISCUSSION}

Fluorescent reporter proteins are useful tools for plant-microbe interaction studies $(13,45)$. In the present study, efficient PEGmediated transformation of protoplasts from hyphae with an sGFP vital marker gene was developed for $P$. chlamydospora, one of the fungal species involved in the grape Esca disease complex.

The selected transformant Pch-sGFP71 line was used to analyze in situ $P$. chlamydospora spread in grapevine cultivars and rootstock tissues. To select a stable $P$ ch-sGFP line, the transformants were characterized for $s g f p$ and $h p h$ genome insertion and sGFP fluorescence emission using qPCR and fluorimetric systems, respectively. It is worth noting that there was low correlation between the relative $s g f p$ copy numbers and the sGFP fluorescence expressed across the nine Pch-sGFP lines selected. Thus, the levels of expression of sGFP in each transformant appeared to be determined not only by gene copy number but also

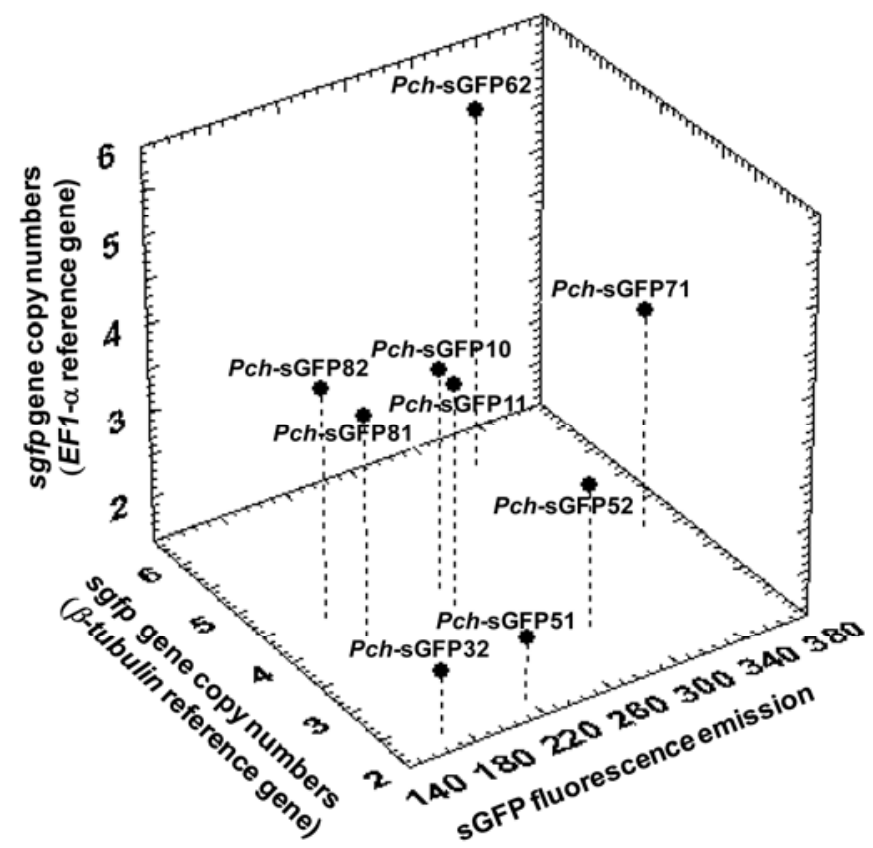

Fig. 2. Relationships between the number of synthetic green fluorescent protein $(s g f p)$ gene copies in the transgenic Phaeomoniella chlamydospora $(P c h)$-sGFP lines, calculated using quantitative polymerase chain reaction and relative to the $\beta$-tubulin reference gene, the elongation factor $1-\alpha(E F 1-\alpha)$ reference gene, and sGFP expression as measured by fluorescence microscopy. Data were correlated using the Pearson linear correlation method $(P \leq$ $0.05)$. by different factors, including genomic location and arrangements of the integrate genes $(29,37)$. Transgene copy numbers and sGFP expression levels can be positively correlated or not correlated, as has been reported previously $(18,33)$.

Using sGFP-transformed $P$. chlamydospora, we proposed a new strategy for the detection of this fungal species in inoculated grapevine cuttings. Unlike nucleic acid-based approaches, using sGFP-expressing $P$. chlamydospora provides topological information on the spread of the fungus within the grapevine plant. Moreover, we were able to detect the presence of $P$. chlamydospora before the expression of any internal Esca disease symptoms (dark streaking) on the cuttings. Therefore, our approach represents an efficient way for analyzing grapevine wood colonization in vivo. Moreover, the GFP technology applied to P. chlamydospora revealed that fungal presence was limited to the wood tissues in all of the cultivars and rootstocks analyzed. This is evidence that the sGFP-transformed $P$. chlamydospora maintained its pathogenicity and was able to express the sGFP protein in the hyphae of the fungus both in vitro and in vivo.

In our study, the specific green fluorescence was particularly concentrated around the vessels while no green fluorescence was detected in the vessel lumens. The vessel lumens inside the areas infected by Pch-sGFP71 line showed typical occlusion, which was visible under the microscope as an orange coloration. The production of these compounds, the source of which appears to be axial parenchyma cells, and as also demonstrated by Sun et al. (39), was observed only in areas showing brilliant green fluorescence. It is known that this pathogen induces the production of tyloses or gels that can result in the occlusion of the vessels (43). In particular, these substances might be related to the phytotoxic pullulans (exopolysaccharides) $(3,8)$ or phenolic compounds $(2,20,21,27,42,43)$ that can be produced in response to infection. In vascular diseases, tyloses and other occluding materials (gels or gums) have generally been considered to be active defense mechanisms that can limit the growth of pathogenic microorganisms (11). On the other hand, previous studies have suggested that the principal role of $P$. chlamydospora in the early stages of the disease could be to reduce the plant resistance through its toxic activity $(2,8,20,32)$, thus opening the way to other fungi that are more strictly related to enzymatic wood degradation (44).

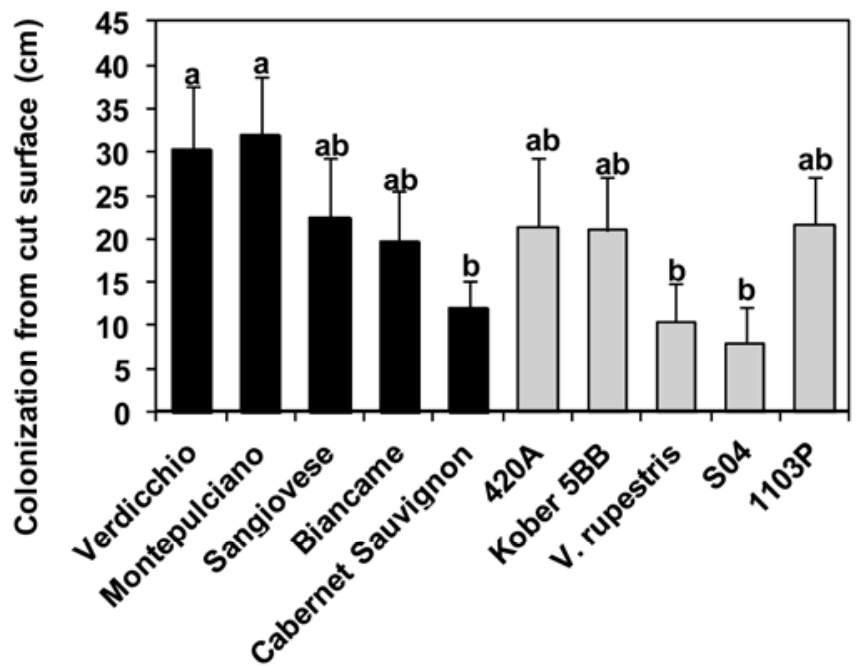

\section{Grapevine cultivars and rootstocks}

Fig. 3. Phaeomoniella chlamydospora synthetic green fluorescent protein (Pch-sGFP) 71 colonization observed with inoculated cuttings of grapevine cultivars (Vitis spp.) and rootstocks (as indicated) incubated at $25 \pm 1^{\circ} \mathrm{C}$. Data are means ( \pm standard deviation) of 30 different cuttings for each cultivar and rootstock. Values with different letters are significantly different according to Duncan's multiple range test $(P<0.05)$. 



Fig. 4. Green fluorescence detection using an epifluorescent microscope (Diaphot TMD inverted microscope by blue filter block B-2A ex 450 to 490 em BA520) (Nikon, Tokyo) of the transgenic Phaeomoniella chlamydospora synthetic green fluorescent protein (Pch-sGFP)71 line in inoculated grapevine cuttings. Proliferation of $P c h$-sGFP71 mycelia obtained from the basal section of inoculated 'Sangiovese' grape cuttings kept for 6 months at $4 \pm 1{ }^{\circ} \mathrm{C}$ and then incubated at $25 \pm 1{ }^{\circ} \mathrm{C}$ for $\mathbf{A}, 72 \mathrm{~h}$ and $\mathbf{B}, 96 \mathrm{~h}$, respectively. C to F, Sections from Sangiovese grape cuttings inoculated with the $P c h$-sGFP71 line and observed after incubation at $25 \pm 1{ }^{\circ} \mathrm{C}$ for 6 months show an intense sGFP green fluorescence in xylem area. C, Transverse section of inoculated cuttings showing obstructed vessels (orange) surrounded by green fluorescence, while other vessels without green fluorescence are empty (see arrows). D, sGFP green fluorescence localized around vessels in the parenchymal cells surrounding xylem fibers (arrow). E, Longitudinal section showing Pch-sGFP71 colonization of the wood. F, Longitudinal section showing the presence of orange material in xylem vessel surrounded by $P c h$-sGFP71 colonization. No sGFP expression was observed into the vessels of the longitudinal sections (arrows). Control $=\mathbf{G}$, transverse section and $\mathbf{H}$, longitudinal section of Sangiovese grape noninoculated cuttings. Scale bars $=100 \mu \mathrm{m}$. 
In the present study, the Pch-sGFP71 line colonized the wood tissues and, after 6 months at $25 \pm 1{ }^{\circ} \mathrm{C}$, different rates of colonization were seen across these cultivars and rootstocks of Vitis spp. that have considerable commercial interest. In particular, Verdicchio and Montepulciano showed the highest values for $P c h$-sGFP71 fungal invasion, while the lowest value was recorded for Cabernet Sauvignon. In the literature, however, Cabernet Sauvignon is reported as one of the most sensitive varieties, based on Esca foliar symptoms (6). As expected, it is not always possible to correlate Esca sensitivity based on wood colonization and foliar symptoms, whose severity depends on different factors (microorganisms, climate conditions, cultivar susceptibilities, vineyard characteristics, and rootstock) $(26,35,40)$. The differences observed in the extent of colonization might depend on several factors. Among these are the differential abilities of the pathogen to colonize both cultivar or rootstock, and the variations in the structural and chemical characteristics of the host tissue. Some studies have reported a lower hydraulic conductance of rootstocks compared with the cultivars $(10,41)$. This can justify the tendency toward an overall lower mean colonization extent observed in the rootstocks compared with the cultivars. Different degrees of $P$. chlamydospora colonization were also observed among grapevine genotypes (14).

A further observation was related to the different $P$ ch-sGFP71 development responses observed relative to the incubation temperatures. As expected, despite a complete inhibition of the spread of $P$ ch-sGFP71 as seen for the cuttings incubated at $4 \pm$ $1{ }^{\circ} \mathrm{C}$, the in vitro reisolation and the development at $25 \pm 1{ }^{\circ} \mathrm{C}$ revealed that low temperatures do not affect the viability of the fungus. For this reason, these data highlight the need to check each step in the production of grapevine-propagating materials because, once they are contaminated, they represent an important carrier of the fungi involved in Esca disease into newly established vineyards, even when the cuttings are cold stored $(4,46)$.

To our knowledge, these are the first data in which sGFP has been used to study $P$. chlamydospora colonization in grapevine cuttings. Thus, this information will help to provide a better understanding of the $P$. chlamydospora colonization levels of grapevine cultivars and rootstocks, with the aim of predicting the possible susceptibilities of plants to Esca disease. However, further trials using a wider range of grapevine cultivars are necessary to confirm these observations. The system also allowed us to detect $P$. chlamydospora plant colonization before the black streaking symptoms are expressed. Furthermore, the use of this sGFP-transformed $P$. chlamydospora has been helpful for the clarification of different aspects associated with the localization of this pathogen and for providing information to design a sanitation program in order to improve the quality of grapevine plant material.

\section{ACKNOWLEDGMENTS}

The research study was commissioned from ARSIA-Toscana (Regional Agency for Development and Innovation in Agriculture and Forest) by 14 administrative regions and one autonomous province, and financed with funds provided by the Ministero per le Politiche Agricole e Forestali (Ministry for Agriculture and Forestry Policy, Italy) to implement the inter-Regional Project Grapevine Esca: research and experiment in the nursery and in the field for prevention and cure. We thank G. Surico (University of Florence, Italy) for kindly providing CBS 229.95 isolate of Phaeomoniella chlamydospora and F. Faretra (University of Bari, Italy) for kindly providing the primers for the detection of $P$. chlamydospora.

\section{LITERATURE CITED}

1. Abbatecola, A., Pollastro, S., Pichierri, A., and Faretra, F. 2006. Survey on the presence of Phaeomoniella chlamydospora in grapevine rootstocks. J. Plant Pathol. 88:S31.

2. Agrelli, D., Amalfitano, C., Conte P., and Mugnai, L. 2009. Chemical and spectroscopic characteristics of the wood of Vitis vinifera cv. Sangiovese affected by Esca disease. J. Agric. Food Chem. 57:11469-11475.

3. Andolfi, A., Cimmino, A., Evidente, A., Iannaccone, M., Capparelli, R., Mugnai, L., and Surico, G. 2009. A new flow cytometry technique to identify Phaeomoniella chlamydospora exopolysaccharides and study mechanisms of Esca grapevine foliar symptoms. Plant Dis. 93:680-684.

4. Aroca, A., Gramaje, D., Armengol, J., García-Jiménez, J., and Raposo, R. 2010. Evaluation of the grapevine nursery propagation process as a source of Phaeoacremonium spp. and Phaeomoniella chlamydospora and occurrence of trunk disease pathogens in rootstock mother vines in Spain. Eur. J. Plant Pathol. 126:165-174.

5. Bertelli, E., Mugnai, L., and Surico, G. 1998. Presence of Phaeoacremonium chlamydosporum in apparently healthy rooted grapevine cuttings. Phytopathol. Mediterr. 37:79-82.

6. Borgo, M., Bellotto, D., Dal Cortivo, G. L., Zanzotto, A., Tosi, E., and Marchesini, E. 2008. Sensibilità varietale al mal dell'esca della vite nel Veneto. Atti Giornate Fitopatol. 2:223-230.

7. Bradshow, R. E., Duan, G., and Long, P. G. 2005. Transformation of fungal grapevine trunk disease pathogens with the green fluorescent protein gene. Phytopathol. Mediterr. 44:162-168.

8. Bruno, G., and Sparapano, L. 2006. Effects of three Esca associated fungi on Vitis vinifera L.: II. Characterization of biomolecules in xylem sap and leaves of healthy and diseased vines. Physiol. Mol. Plant. Pathol. 69:195208.

9. Chiarappa, L. 1959. Wood decay of the grapevine and its relationship with black measles disease. Phytopathology 49:510-519.

10. Clearwater, M. J., Lowe, R. G., Hofstee, B. J., Barclay, C., Mandemaker, A. J., and Blattmann, P. 2004. Hydraulic conductance and rootstock effects in grafted vines of kiwifruit. J. Exp. Bot. 55:1371-1382.

11. Clérivet, A., Déon, V., Alami, I., Lopez, F., Geiger, J. P., and Nicole, M. 2000. Tyloses and gels associated with cellulose accumulation in vessels are responses of plane tree seedlings (Platanus $\times$ acerifolia) to the vascular fungus Ceratocystis fimbriata $\mathrm{f}$. sp. platani. Trees 15:25-31.

12. Crous, P. W., and Gams, W. 2000. Phaeomoniella chlamydospora gen. et comb. nov., a causal organism of Petri grapevine decline and esca. Phytopathol. Mediterr. 39:112-118.

13. de Silva, A. P., Bolton M. D., and Nelson, B. D. 2009. Transformation of Sclerotinia sclerotiorum with the green fluorescent protein gene and fluorescence of hyphae in four inoculated hosts. Plant Pathol. 58:487-496.

14. Eskalen, A., Feliciano, J., and Gubler, W. D. 2007. Susceptibility of grapevine pruning wounds and symptom development in response to infection by Phaeoacremonium aleophilum and Phaeomoniella chlamydospora. Plant Dis. 91:1100-1104.

15. Fourie, P. H., and Halleen, F. 2004. Occurrence of grapevine trunk disease pathogens in rootstock mother plants in South Africa. Australas. Plant Pathol. 33:313-315.

16. Gang, L., Ruixue, L., Qiuyun, L., Qiang, W., Min, C., and Baojian, L. 2006. A highly efficient polyethylene glycol-mediated transformation method for mushrooms. FEMS Microbiol. Lett. 256:203-208.

17. Halleen, F., Crous, P. W., and Petrini, O. 2003. Fungi associated with healthy grapevine cuttings in nurseries, with special reference to pathogens involved in the decline of young vines. Australas. Plant Pathol. 32:47-52.

18. Hobbs, S. L. A., Warkentin, T. D., and DeLong, C. M. O. 1993. Transgene copy number can be positively or negatively associated with transgene expression. Plant. Mol. Biol. 21:17-26.

19. Larignon, P., and Dubos, B. 1997. Fungi associated with esca disease in grapevine. Eur. J. Plant Pathol. 103:147-157.

20. Letousey, P., Baillieul, F., Perrot, G., Rabenoelina, F., Boulay, M., Vaillant-Gaveau, N., Clément, C., and Fontaine, F. 2010. Early events prior to visual symptoms in the apoplectic form of grapevine. Phytopathology 100:424-431.

21. Lima, M. R. M., Felgueiras, M. L., Graça, G., Rodrigues, J. E. A., Barros A., Gil, A. M., and Dias, A. C. P. 2010. NMR metabolomics of Esca diseaseaffected Vitis vinifera cv. Alvarinho leaves. J. Exp. Bot. 61:4033-4042.

22. Lippincott-Schwartz, J., and Patterson, G. 2003. Development and use of fluorescent protein markers in living cells. Science 300:87-91.

23. Livak, K. J., and Schmittgen, T. D. 2001. Analysis of relative gene expression data using real-time quantitative PCR and the $2^{-\Delta \Delta C(T)}$ method. Methods 25:402-408.

24. Lorang, J. M., Tuori, R. P., Martinez, J. P., Sawyer, T. L., Redman, R. S., Rollins, J. A., Wolpert, T. J., Johnson, K. B., Rodriguez, R. J., Dickman, M. B., and Ciuffetti, L. M. 2001. Green fluorescent protein is lighting up fungal biology. Appl. Environ. Microbiol. 67:1987-1994.

25. Maciá-Vicente, J. M., Jansson, H. B., Talbot, N. J., and Lopez-Llorca, L. V. 2009. Real-time PCR quantification and live-cell imaging of endophytic colonization of barley (Hordeum vulgare) roots by Fusarium equiseti and Pochonia chlamydosporia. New Phytol. 182:213-228.

26. Marchi, G. 2001. Susceptibility to Esca of various grapevine (Vitis vinifera) cultivars grafted on different rootstocks in a vineyard in the province of Siena (Italy). Phytopathol. Mediterr. 40:27-36. 
27. Martin, N., Vesentini, D., Rego, C., Monteiro, S., Oliveira, H., and Boavida Ferreira, R. 2009. Phaeomoniella chlamydospora infection induces changes in phenolic compounds content in Vitis vinifera. Phytopathol. Mediterr. 48:101-106.

28. McLean, T., Fourie, P. H., and McLeod, A. 2009. Reporter gene transformation of the trunk disease pathogen Phaeomoniella chlamydospora and biological control agent Trichoderma harzianum. Australas. Plant Pathol. 38:153-167.

29. Michielse, C. B., Hooykaas, P. J. J., van den Hondel, C. A. M. J., and Ram, A. F. J. 2005. Agrobacterium-mediated transformation as a tool for functional genomics in fungi. Curr. Genet. 48:1-17.

30. Mugnai, L., Graniti, A, and Surico, G. 1999. Esca (Black méasles) and brown woodstreaking: Two old and elusive diseases of grapevines. Plant Dis. 83:404-417.

31. Murray M. G., and Thompson, W. F. 1980. Rapid isolation of high molecular weight DNA. Nucleic Acids Res. 8:4321-4325.

32. Petit, A.-N., Vaillant, N., Boulay, M., Clément, C., and Fontaine, F. 2006. Alteration of photosynthesis in grapevines affected by Esca. Phytopathology 96:1060-1066.

33. Riedel, M., Calmin, G., Belbahri, L., Lefort, F., Götz, M., Wagner, S. and Werres, S. 2009. Green fluorescent protein (GFP) as a reporter gene for the plant pathogenic oomycete Phytophthora ramorum. J. Eukaryot. Microbiol. 56:130-135.

34. Romanazzi, G., Mlikota Gabler, F., and Smilanick, J. L. 2006. Preharvest chitosan and postharvest UV-C irradiation treatments suppress gray mold of table grapes. Plant Dis. 90:445-450.

35. Romanazzi, G., Murolo, S., Pizzichini, L., and Nardi, S. 2009. Esca in young and mature vineyards, and molecular diagnosis of the associated fungi. Eur. J. Plant Pathol. 125:277-290.

36. Rozen, S., and Skaletsky, H. J. 2000. Primer3 on the WWW for general users and for biologist programmers. Pages 365-386 in: Bioinformatic Methods and Protocols: Methods in Molecular Biology. S. Krawetz and S. Misener, eds. Humana Press, Totowa, NJ.
37. Si-Ammour, A., Mauch-Mani, B., and Mauch, F. 2003. Quantification of induced resistance against Phytophthora species expressing GFP as vital marker: $\beta$-aminobutyric acid but not BTH protects potato and Arabidopsis from infection. Mol. Plant Pathol. 4:237-248.

38. Solomon, P. S., Lowe, R. G. T., Trengove, R. D., Rechberger, J., and Oliver, R. P. 2006. Normalisation of metabolites in heterogenous systems using genomics. Anal. Biochem. 350:156-158.

39. Sun, Q., Rost, T. L., and Matthews, M. A. 2008. Wound-induced vascular occlusions in Vitis vinifera (Vitaceae): Tyloses in summer and gels in winter. Am. J. Bot. 95:1498-1505.

40. Surico, G., Mugnai, L., and Marchi, G. 2006. Older and more recent observations on esca: A critical overview. Phytopathol. Mediterr. 45:S68S86.

41. Syvertsen, J. P. 1981. Hydraulic conductivity of four commercial citrus rootstocks. J. Am. Soc. Hortic. Sci. 106:378-381.

42. Tabacchi, R., Fkyerat, A., Poliart, C., and Dubin, G. M. 2000. Phytotoxins from fungi of Esca grapevine. Phytopathol. Mediterr. 39:156-161.

43. Troccoli, L., Calmassi, R., Mori, B., Mugnai, L., and Surico, G. 2001. Phaeomoniella chlamydospora-grapevine interaction: Histochemical reactions to fungal infection. Phytopathol. Mediterr. 40:S400-S406.

44. Valtaud, C., Larignon, P., Roblin, G., and Fleurat-Lessard, P. 2009. Developmental and ultrastructural features of Phaeomoniella chlamydospora and Phaeoacremonium aleophilum in relation to xylem degradation in Esca disease of the grapevine. J. Plant Pathol. 91:37-51.

45. Venard, C., and Vaillancourt, L. 2007. Colonization of fiber cells by Colletotrichum graminicola in wounded maize stalks. Phytopathology 97:438-447.

46. Whiteman, S. A., Stewart, A., Ridgway, H. J., and Jaspers M. V. 2007. Infection of rootstock mother-vines by Phaeomoniella chlamydospora results in infected young grapevines. Australas. Plant Pathol. 36:198-203.

47. Widholm, J. M. 1972. The use of fluorescein diacetate and phenosafranine for determining viability of cultured plant cells. Stain Tech. 47:89-94. 